\title{
Effectiveness of Delivering Key Points in Biochemistry on improvement of academic performance and attitude of first year MBBS students
}

\author{
Santhi Silambanan', Manikandan $\mathrm{A}^{2}$, Kamalam $\mathbf{R}^{3}$, Shalini $\mathrm{L}^{4}$ \\ 1,2,3,4 Department of Biochemistry, Sri Ramachandra Medical College and Research Institute, Sri Ramachandra Institute of Higher \\ Education\& Research (SRIHER), Chennai, Tamil Nadu, India. \\ ${ }^{1}$ santhisilambanan@sriramachandra.edu.in, ${ }^{2}$ manikandan@ sriramachandra.edu.in, ${ }^{3}$ kamalamr@sriramachandra.edu.in \\ ${ }^{4}$ shalini.1@sriramachandra.edu.in
}

\begin{abstract}
Introduction: The undergraduate students have difficulty in achieving good academic performance in Biochemistry subject. In spite of using various teaching methodologies the teacher is not able to create interest in the subject as well as improve knowledge. This study was undertaken to assess the efficacy of delivering key points on the improvement in academic performance as well as changing their perception about Biochemistry amongst first year MBBS students.

Methods: The study was conducted by the Department of Biochemistry in Sri Ramachandra Medical College and Research Institute in the year 2016. Students of 2015 batch were provided with important points in the proper format which were prepared by the faculty. Formative assessment examination marks were compared with students of previous four batches. Also, the perception of delivery of key points was assessed. Ethics approval was obtained from the institutional ethics committee (IECNI/16/AUG/55/63). Statistical analysis was done using SPSS version16.0. $\mathrm{p}<0.05$ was considered significant. No funding was obtained for conducting this study.
\end{abstract}

Results: There was significant increase in the performance of the students in the formative assessment examinations. The students' responses were positive in more than $80 \%$ in all the items of the survey questionnaire.

Conclusion: There was improvement in the academic performance of the students. They said it was useful for understanding and preparing for the examinations.

Keywords

notes, e-resources, lecture guides, flow charts, handouts

Article Received: 10 August 2020, Revised: 25 October 2020, Accepted: 18 November 2020

\section{Introduction}

Biochemistry is taught during the first year of undergraduate medical curriculum. The allotted hours for teaching Biochemistry may be appropriate for the contents to be delivered to the students. But the complexity of the subject is so high, that the teachers have difficulty in making the students understand the concepts. Over the years this has brought a change in the attitude of the students in the form of fear or aversion towards Biochemistry. This study was undertaken to make studying easier thus stimulating the students to start learning Biochemistry on their own. If the students are provided with the key points which are the ones expected out of them, their ability to retain and reproduce the same in the examinations will be better. If done over a period, could give them confidence; and this might change the attitude of the students towards the subject. This study was undertaken to study the effectiveness of giving the key points in Biochemistry on the improvement of academic performance as well as assess the change in the attitude of the students towards Biochemistry subject.

\section{Methods:}

The study was conducted by the Department of Biochemistry in Sri Ramachandra Medical College and Research Institute in the year 2016. From 2006 we have been following integrated curriculum which has both horizontal as well as vertical components. The integrated curriculum is divided into six blocks according to the physiological systems. First year MBBS students from the batches 2011 to 2015 were included in the study. Academic Performances in the formative assessment or internal assessment (IA) examinations conducted at the end of each block were compiled from 250 students of each batch. Students of 2015 batch were provided with 
important or key points for most of the topics. The study materials were prepared by all the faculty members; they were further edited and uploaded onto the intranet available within the institution. The students were able to access the same at any time with their login details. Also the students were provided with the disclaimer at the beginning of reading materials of each block and were as follows:

"Dear students,

$>$ Answers in the form of key points have been provided for possible questions which can be asked in the examination. If you write those points there is more probability of passing in the exam. But if you are interested in getting more marks you are expected to refer the prescribed textbooks in addition. For answering multiple choice questions, you have to read the complete chapter.

$>$ When you go through the answers you will see that the font color is different in various areas. Black color font indicates that those points you must know and you cannot miss any point given in that color. Blue colored font indicates that those points are desirable to know; if you add them to the answers you will fetch more marks. Red colored font indicate that these points are interesting to know and can be little tougher; if you think you are confident enough to include, you can do so.

Marks obtained by students of 2015 batch in the formative assessment examinations were compared with students of batches 2011 to 2014 . One way Analysis of Variance (ANOVA) and Tukey post-hoc tests were the statistical tools used. The students of the 2015 batch after they had entered paraclinical years were included for further study. In the batch of 250, 144 students expressed their willingness to participate in the study. They were given survey questionnaire of ten items in five-point Likert rating scale to express their experiences of using key points in their studies. The anonymity of the students was maintained throughout the study. Mean, standard deviation, median, mode, interquartile range and $\mathrm{Z}$-score were derived. There were also two open ended questions which allowed them to express what they felt were good and what were the areas which needed improvement. Coding of the comments given to the two open ended questions were done and analyzed. Statistical analysis of the data was done using SPSS version16.0. $p<0.05$ was considered significant. Ethics approval was obtained from the institutional ethics committee (IEC-NI/16/AUG/55/63, dt 29-06-2016). No funding was obtained for conducting this study.

\section{Results:}

The marks obtained by the students in the six internal assessment examinations of the five batches from the year 2011 to 2015 were compared using one way ANOVA. There were statistical significant differences $(\mathrm{P}<0.0001)$ in the academic performance of students of 2015 batch when compared with other four batches. The ANOVA results obtained is not displayed in the form of a table since the level of significance is the same across the blocks. Tukey Post-hoc test was done to show the statistical significant difference between the blocks across the years. (table 1).

Table 1: Tukey post hoc analysis of the various batches across the blocks

\begin{tabular}{|l|l|l|l|l|}
\hline $\begin{array}{l}\text { Internal } \\
\text { Assessme } \\
\text { nt exam } \\
\begin{array}{l}2015 \\
\text { batch) }\end{array}\end{array}$ & $\begin{array}{l}\text { 2011 } \\
\text { batch } \\
\text { value }\end{array}$ & $\begin{array}{l}2012 \\
\text { batch } \\
P \\
\text { value }\end{array}$ & $\begin{array}{l}\text { 2013 } \\
\text { batch } \\
P \\
\text { value }\end{array}$ & $\begin{array}{l}2014 \\
\text { batch } \\
P \\
\text { value }\end{array}$ \\
\hline I IA & $\begin{array}{l}0.000^{*} \\
*\end{array}$ & $\begin{array}{l}0.000^{*} \\
*\end{array}$ & $\begin{array}{l}0.000^{*} \\
*\end{array}$ & $\begin{array}{l}0.000^{*} \\
*\end{array}$ \\
\hline II IA & $\begin{array}{l}0.001^{*} \\
*\end{array}$ & $\begin{array}{l}0.000^{*} \\
*\end{array}$ & $0.027^{*}$ & $\begin{array}{l}0.000^{*} \\
*\end{array}$ \\
\hline III IA & $\begin{array}{l}0.000^{*} \\
*\end{array}$ & $\begin{array}{l}0.000^{*} \\
*\end{array}$ & $\begin{array}{l}0.000^{*} \\
*\end{array}$ & $\begin{array}{l}0.000^{*} \\
*\end{array}$ \\
\hline IV IA & $\begin{array}{l}0.000^{*} \\
*\end{array}$ & $0.029^{*}$ & $\begin{array}{l}0.000^{*} \\
*\end{array}$ & $\begin{array}{l}0.000^{*} \\
*\end{array}$ \\
\hline V IA & $\begin{array}{l}0.000^{*} \\
*\end{array}$ & $0.032^{*}$ & $0.040^{*}$ & 0.344 \\
\hline VI IA & 0.999 & $\begin{array}{l}0.000^{*} \\
*\end{array}$ & $\begin{array}{l}0.000^{*} \\
*\end{array}$ & $\begin{array}{l}0.004^{*} \\
*\end{array}$ \\
\hline
\end{tabular}

(IA: Internal Assessment; ${ }^{* *} P$ value $<0.00$ : highly significant; $* P$ value $<0.05$ :significant)

In the 250 students of batch 2015, 144 students participated in further study. They were given ten item survey questionnaire to give their responses in five point Likert rating scale 
Table 2: Responses to ten item survey questionnaire of the five-point Likert scale regarding the training involving key points by students of 2015 batch $(n=144)$

\begin{tabular}{|c|c|c|c|c|c|c|c|}
\hline \multirow[b]{2}{*}{$\begin{array}{l}\text { S. } \\
\text { NO. }\end{array}$} & \multirow[b]{2}{*}{ Items } & SDA & DA & UD & A & SA & \multirow{2}{*}{$\begin{array}{l}\text { Positive } \\
\text { responses } \\
(\mathrm{A}+\mathrm{SA}) \\
\mathrm{n}(\%)\end{array}$} \\
\hline & & $\begin{array}{l}\mathrm{n} \\
(\%)\end{array}$ & $\begin{array}{l}\mathrm{n} \\
(\%)\end{array}$ & $\begin{array}{l}\mathrm{n} \\
(\%)\end{array}$ & $\begin{array}{l}\mathrm{n} \\
(\%)\end{array}$ & $\begin{array}{l}\mathrm{n} \\
(\%)\end{array}$ & \\
\hline 1 & $\begin{array}{l}\text { Key points were provided to most of the } \\
\text { topics covered in Biochemistry }\end{array}$ & $\begin{array}{l}6 \\
(4 \%)\end{array}$ & $3(2 \%)$ & $3(2 \%)$ & $\begin{array}{l}64 \\
(44 \%)\end{array}$ & $\begin{array}{l}68 \\
(47 \%)\end{array}$ & $\begin{array}{l}132 \\
(92 \%) \\
\end{array}$ \\
\hline 2 & $\begin{array}{l}\text { Training met the objectives mentioned } \\
\text { in the sessions }\end{array}$ & $\begin{array}{l}0 \\
(0 \%)\end{array}$ & $9(6 \%)$ & $9(6 \%)$ & $\begin{array}{l}75 \\
(52 \%)\end{array}$ & $\begin{array}{l}51 \\
(35 \%)\end{array}$ & $\begin{array}{l}126 \\
(88 \%)\end{array}$ \\
\hline 3 & $\begin{array}{l}\text { Presentation of the topics made } \\
\text { interesting to learn }\end{array}$ & $\begin{array}{l}2 \\
(1 \%)\end{array}$ & $\begin{array}{l}1 \\
1(8 \%)\end{array}$ & $\begin{array}{l}23 \\
(16 \%)\end{array}$ & $\begin{array}{l}68 \\
(47 \%)\end{array}$ & $\begin{array}{l}40 \\
(28 \%)\end{array}$ & $\begin{array}{l}108 \\
(75 \%)\end{array}$ \\
\hline 4 & $\begin{array}{l}\text { All the topics given to us were useful } \\
\text { for preparing for examinations }\end{array}$ & $\begin{array}{l}2 \\
(1 \%)\end{array}$ & $8(6 \%)$ & $\begin{array}{l}11 \\
(7 \%)\end{array}$ & $\begin{array}{l}55 \\
(38 \%)\end{array}$ & $\begin{array}{l}68 \\
(47 \%)\end{array}$ & $\begin{array}{l}123 \\
(85 \%)\end{array}$ \\
\hline 5 & I referred all the topics provided to us & $\begin{array}{l}3 \\
(2 \%)\end{array}$ & $\begin{array}{l}16 \\
(11 \%)\end{array}$ & $6(4 \%)$ & $\begin{array}{l}69 \\
(48 \%)\end{array}$ & $\begin{array}{l}50 \\
(35 \%)\end{array}$ & $\begin{array}{l}119 \\
(83 \%)\end{array}$ \\
\hline 6 & $\begin{array}{l}\text { I could access the key points anytime I } \\
\text { wanted to refer }\end{array}$ & $\begin{array}{l}1 \\
(1 \%)\end{array}$ & $6(4 \%)$ & $5(3 \%)$ & $\begin{array}{l}60 \\
(42 \%)\end{array}$ & $\begin{array}{l}72 \\
(50 \%)\end{array}$ & $\begin{array}{l}132 \\
(92 \%)\end{array}$ \\
\hline 7 & $\begin{array}{l}\text { Enough time for available to prepare for } \\
\text { internal assessment examinations using } \\
\text { key points }\end{array}$ & $\begin{array}{l}2 \\
(1 \%)\end{array}$ & $\begin{array}{l}11 \\
(8 \%)\end{array}$ & $8(6 \%)$ & $\begin{array}{l}64 \\
(44 \%)\end{array}$ & $\begin{array}{l}59 \\
(41 \%)\end{array}$ & $\begin{array}{l}123 \\
(85 \%)\end{array}$ \\
\hline 8 & $\begin{array}{l}\text { Presentation of key points improved my } \\
\text { academic performance in internal } \\
\text { assessment examinations }\end{array}$ & $\begin{array}{l}2 \\
(1 \%)\end{array}$ & $5(3 \%)$ & $9(6 \%)$ & $\begin{array}{l}70 \\
(49 \%)\end{array}$ & $\begin{array}{l}58 \\
(40 \%)\end{array}$ & $\begin{array}{l}128 \\
(89 \%)\end{array}$ \\
\hline 9 & I have started liking Biochemistry & $\begin{array}{l}3 \\
(2 \%)\end{array}$ & $\begin{array}{l}10 \\
(7 \%)\end{array}$ & $\begin{array}{l}20 \\
(14 \%)\end{array}$ & $\begin{array}{l}61 \\
(42 \%)\end{array}$ & $\begin{array}{l}50 \\
(35 \%)\end{array}$ & $\begin{array}{l}111 \\
(77 \%)\end{array}$ \\
\hline 10 & $\begin{array}{l}\text { Training motivated me to start in-depth } \\
\text { reading of Biochemistry. }\end{array}$ & $\begin{array}{ll}2 \\
(1 \%)\end{array}$ & $11(8 \%)$ & $\begin{array}{l}15 \\
(10 \%)\end{array}$ & $\begin{array}{l}62 \\
(43 \%)\end{array}$ & $\begin{array}{l}54 \\
(38 \%)\end{array}$ & $116(81 \%)$ \\
\hline
\end{tabular}

(SDA: Strongly disagree=1, DA: Disagree=2, UD: Undecided=3, A: Agree=4, SA: Strongly Agree=5)

Table 3 The statistical analysis of responses obtained from the ten items survey questionnaire

\begin{tabular}{|l|l|l|l|l|l|l|l|l|l|l|}
\hline & \multicolumn{2}{|l|}{ Survey questionnaire Items of 5-point Likert scale } \\
\cline { 2 - 12 } & 1 & 2 & 3 & 4 & 5 & 6 & 7 & 8 & 9 & 10 \\
\hline $\begin{array}{l}\text { Total } \\
\text { responses }\end{array}$ & 617 & 600 & 565 & 611 & 579 & 628 & 599 & 609 & 577 & 587 \\
\hline $\begin{array}{l}\text { Positive } \\
\text { responses } \\
(\%)\end{array}$ & $\begin{array}{l}596 \\
(97 \%)\end{array}$ & $\begin{array}{l}555 \\
(93 \%)\end{array}$ & $\begin{array}{l}472 \\
(84 \%)\end{array}$ & $\begin{array}{l}560 \\
(92 \%)\end{array}$ & $\begin{array}{l}526 \\
(91 \%)\end{array}$ & $\begin{array}{l}600 \\
(96 \%)\end{array}$ & $\begin{array}{l}551 \\
(92 \%)\end{array}$ & $\begin{array}{l}570 \\
(94 \%)\end{array}$ & $\begin{array}{l}494 \\
(86 \%)\end{array}$ & $\begin{array}{l}518 \\
(88 \%)\end{array}$ \\
\hline $\begin{array}{l}\text { Mean } \\
\text { SD }\end{array}$ & $\begin{array}{l}4.28 \\
\pm\end{array}$ & $\begin{array}{l}4.17 \\
\pm\end{array}$ & $\begin{array}{l}3.92 \\
\pm\end{array}$ & $\begin{array}{l}4.24 \\
\pm\end{array}$ & $\begin{array}{l}4.02 \\
\pm\end{array}$ & $\begin{array}{l}4.36 \\
\pm\end{array}$ & $\begin{array}{l}4.16 \\
\pm\end{array}$ & $\begin{array}{l}4.23 \pm \\
0.93\end{array}$ & $\begin{array}{l}4.01 \pm \\
0.98\end{array}$ & $\begin{array}{l}4.08 \pm \\
0.95\end{array}$ \\
\hline Median & 4 & 4 & 4 & 4 & 4 & 4 & 4 & 4 & 4 & 4 \\
\hline IQR & 1 & 1 & 1.75 & 1 & 1 & 1 & 1 & 1 & 1 & 1 \\
\hline Z Score & 0.30 & 0.21 & -0.08 & 0.26 & 0.02 & 0.45 & 0.17 & 0.28 & 0.01 & 0.08 \\
\hline $\begin{array}{l}Z \\
\text { as score } \\
\text { percentile }\end{array}$ & $62 \%$ & $58 \%$ & $47 \%$ & $60 \%$ & $51 \%$ & $67 \%$ & $57 \%$ & $61 \%$ & $51 \%$ & $53 \%$ \\
\hline
\end{tabular}


(SD: standard deviation; IQR: Interquartile range) The students responded to first open ended question of asking the students to express the best

Figure 1: showing the best aspects of training involving key points
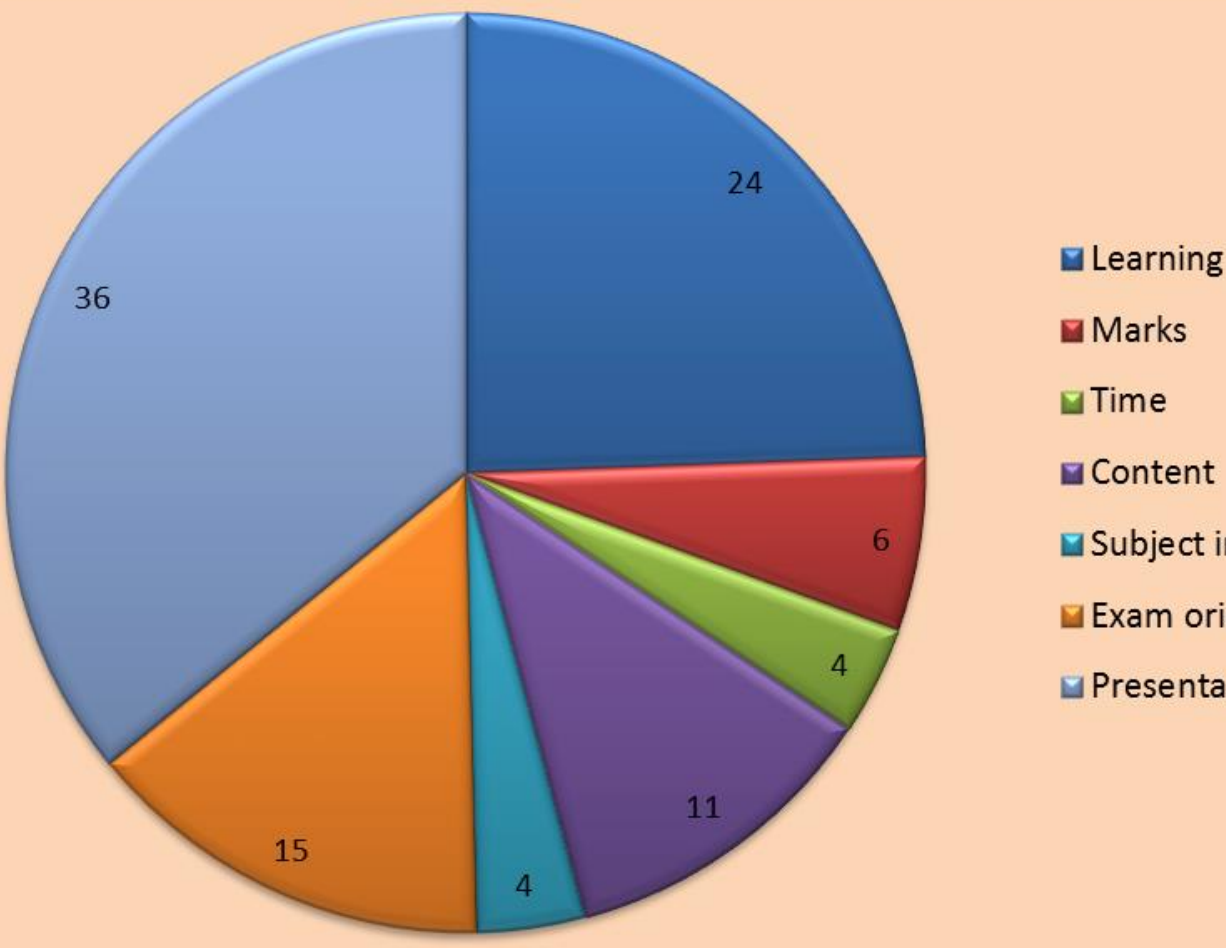

Marks

$\square$ Time

$\square$ Content

$\square$ Subject interest

$\square$ Exam orientation

$\square$ Presentation

Figure 2: showing the aspects of training involving delivery of key points which needed improvement

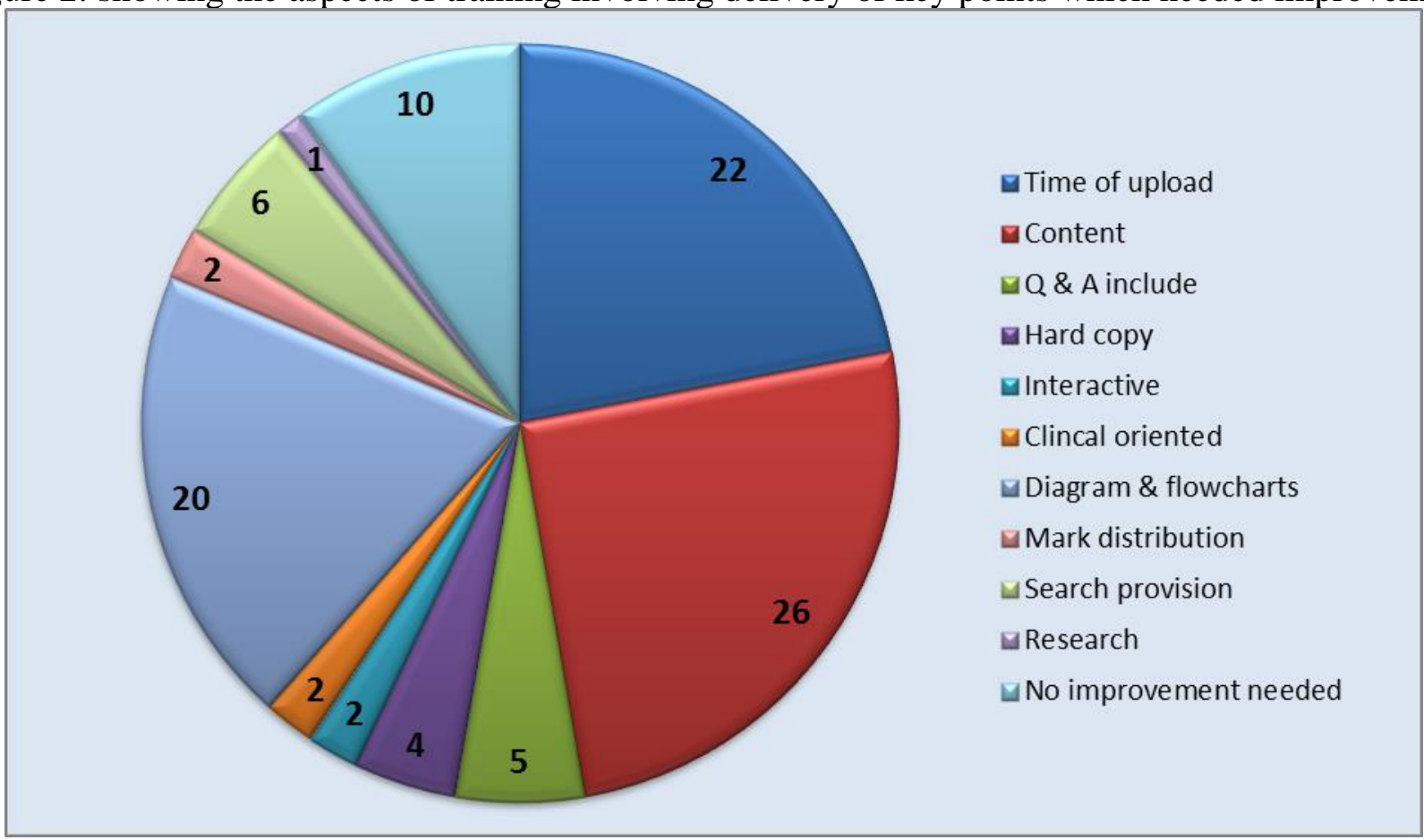

Discussion:

In the medical colleges, the undergraduate students are being guided to study from the prescribed core and reference textbooks. The faculties who handle the didactic lectures provide the students with required information of the session, the objectives of the session, the contents to meet those objectives in the form of power point presentations and their relevant information in the textbooks. The duration of the first year study period of the students is just sufficient to 
read and equip themselves to appear for the formative and summative examinations. The students try to keep pace with regular schedule of teaching, by utilizing the help rendered by teachers, senior students, friends and family members. Despite their sincere efforts, the outcomes are meager. This disengages the students and they tend to get withdrawn. According to undergraduate students, Biochemistry is a very difficult subject with various facts and concepts. It needs a lot of imagination since the molecules which are being taught cannot be demonstrated easily in the form of experiments. Thus the students find it difficult to integrate newly acquired knowledge with already existing one. ${ }^{1}$

It has been a widespread notion about Biochemistry, that it is a dry subject with only facts and there is no correlation between those facts. The only way to remember is by rote memory. ${ }^{2}$ The students memorize and regurgitate in the examination and then completely forget about it. ${ }^{3,4}$ Students are usually passive participants during didactic lectures; with fading of the concentration towards the end of the lecture. ${ }^{5}$ A single lecture may not cater to all students in a class, as the class is composed of individuals of diverse abilities. With the advent of electronic resources teaching and learning is little better than before. ${ }^{6}$

In Sri Ramachandra Medical College and Research Institute, in the first year of MBBS curriculum, the subjects Anatomy, Physiology, Biochemistry and Community Medicine are integrated. ${ }^{7,8}$ It is a problem-based learning (PBL), being exposed to the clinical problems in the beginning of each block. They are allowed to discuss in small groups about the problem along with the basic science knowledge. ${ }^{9}$ Studies have shown that PBL method of teaching could motivate the student to read in-depth about the biochemical concepts, especially in the era high prevalence of computing and information technologies. $^{10}$

Since students are having difficulty in learning and understanding Biochemistry, various innovative measures in the form of concept mapping, creating models, posters, presentations as power points, videos etc. were tried. ${ }^{11}$ The students enjoyed all these initiatives but when it came to improvement of performance in examinations it was not as per the expected outcomes. Hence it was decided to give the important study materials in the form of bulleted key points for the commonly discussed topics. The key points would give an idea about the topic and use the same while reading a textbook. The advantages were improvement in academic performance as well as alleviation of fear and anxiety about Biochemistry. The key points were prepared by the faculties and after editing were uploaded two weeks before the internal assessment examination. There were statistical significant differences ( $\mathrm{P}<0.0001)$ in the academic performance of students of 2015 batch when compared with other four batches. Tukey Post-hoc test was done showed that the performance of the students of the 2015 batch showed statistical significant difference in all the internal assessment examinations when compared from 2011 batch to 2014 batch of students; except on two occasions, one in the fifth IA when 2015 batch was compared against 2014 batch $(P=0.344)$ and in sixth IA when compared with 2011 batch $(P=0.999)$ (Table 1$)$. V block exam was usually conducted as a model exam, which included portions from block I to Block IV. Hence they had difficulty in performing well in that examination. Block VI IA included topics of block $\mathrm{V}$ also, large portion was a challenge for the students to get good academic performance. It was inferred that 2015 batch students performed better in the formative examinations compared to other batch students. Post-hoc analysis also showed that there was better performance between the batches as shown in table 1 . Thus we could say that giving key points had enhanced their academic performance in formative examinations.

We analysed the data obtained from the closed ended questions of ten item survey questionnaire. We found that 132 students (92\%) showed positive response saying that key points were provided to most of the topics dealt in Biochemistry (item1). Around $8 \%$ felt that the key points did not cover all the topics mentioned in the syllabus. To know whether training met the objectives mentioned in the sessions, 126 students (88\%, item 2) were clear that the answers were in alignment with the prior defined objectives; $12 \%$ felt the points were not meeting the objectives defined. Seventy five percent (108 students) had expressed that the points presented were interesting to learn (item 3). Students around 85\% 
that is 123 students were happy that the points given to them were useful in preparing for formative (IA) examinations (item 4). Few students expressed that it was not helpful; this could be students who needed even a simplified version of presentation or it could be very good students whose expectations were very high. These students also expressed vocally that they used the key points only to understand the format or presentation of the contents. With respect to item 5, 119 students (83\%) had referred almost all the key points given to them (table 2). Although, newer innovative teaching modules and curriculum designs have been adopted in various medical schools and universities, the perception of Biochemistry is often considered to be vague by the medical students. This is mainly attributed to the complex chemical structures and the long and interconnecting metabolic cycles. In order to alleviate this distress, a student-centered approach must essentially be adopted, that would focus on 'problem solving' rather than on 'information gathering' skills. To achieve this, it is better to implement a combination of different teaching and learning methods which can serve all the purposes. $^{12}$

The students were comfortable in accessing the key points at whatever time they wanted to study. Ninety two percent that is 132 students gave positive responses with item 6 . With respect to the allotted time available after uploading the key points, 123 students (85\%, item 7) expressed enough time was available for them to prepare for the IA exams using the key points. Generally undergraduate find it difficult to express the points in the proper format. When they were provided with study materials in the bulleted points with flow charts, 128 students (89\%, item 8) expressed it was very useful as a guide to follow so that they would know what to write and what not to write in the examinations. For a student to like a subject it should be easy to understand, and express the same in the examination to fetch more marks. After having obtained a satisfying performance in the formative examinations, 111 students $(77 \%$, item 9) expressed that they had started liking Biochemistry. Even though the percentage of positive responses were little low compared to other items, it was much better than before. Most of the students have disinclination towards the subject. From that point of view, $77 \%$ was taken a great achievement for the effort taken by the faculties. An undergraduate student should be student-centered, self-directed, self-paced and life-long learner to be a competitive professional. For this the student should have interest which might reflect in the form of commitment to learn. Thus in item 10, 81 percent (116 students) had expressed their desire to continue studying Biochemistry in detail. Most of the students learn Biochemistry for the sake of completing the examination or the course. Few students shw interest in learning Biochemistry. But they get discouraged by various factors such as time and boundless curriculum. Most of the textbooks present the contents in an abstract way which is not handled by undergraduate students with ease. Very few books display contents in an easier and understandable presentation, but the information provided may not sufficient for them to meet the outcomes of expected curriculum designed by governing bodies (Table 2). It could be inferred that the responses for all the 10 times were maximum either in the strongly agree or agree rating scale; intermediate response in Undecided scale and the least for Disagree and Strongly Disagree rating scales.

The response was positive of more than $90 \%$ in all the items, except items 3,8 and 9 where the responses were from 80 to $90 \%$. Probably these indicated that the time taken like the subject as well as the adequacy of the reading material provided to them were not up to their expectations. (Table 3) There are lot of discussions regarding which statistical tools to be used to analyze the data obtained by ten item survey questionnaire five point Likert rating scale. The data obtained from ten item survey questionnaire of five point Likert scale were checked for normal distribution of the data obtained. ${ }^{13,14}$ The data did not follow normal distribution. Hence we derived median, mode and interquartile range (IQR). These tools helped to express the magnitude of the responses under each item. Median was found to be 4 for all items. It showed that the responses are strongly polarized towards the positive side. Mode is also used as a statistical measure of central tendency. ${ }^{15}$ Mode was found to be 5 in Likert rating scale, that was strongly agree in items 1,3,5 and 7, whereas it was agree (Likert scale of 4 ) in other items. Hence most of the responses were either strongly agree or agree. The interquartile range was very narrow 
of 1 except in item 3. Narrow interquartile range indicated that the responses were not scattered.

Many studies have also utilized parametric tests for analyzing the data. Hence we decided to find out mean and standard deviation and compare with the statistical information derived from nonparametric tests. ${ }^{16}$ The mean in the Likert scale was more than 4 in all the items except the third item which was 3.97 (Tabel 3). In a Likert rating scale, the numbers used for rating a particular item are not actually the strength of the rating but they are the ranking of the responses given by the study participants. ${ }^{17}$ Likert scale data are ordinal, discrete and have a limited range, which do not form the assumptions of parametric tests. ${ }^{18,19}$ Hence adding the positive, negative and neutral values to get the mean of the responses in each item may reduce the actual effect. Z-score (or normal score) was derived to show how many standard deviations, a mean score of 4.28 (item 1 in table 3) fell above or below the benchmark that is median of 4 . The $\mathrm{Z}$-scores for all the ten items ranged from -0.08 to 0.45 . The $Z$-scores were converted into percentiles which were more than 60 in items 1, 4, 6 and 8 ; between 50 and 60 percentile for the items 2, 5, 7, 9 and 10 and it is 47 for the item 3. By converting the Z-score to percentile the standard Z-score was converted into standardized normal score. This was done to find out which item in the survey questionnaire had a better Z-score relative to the Z-scores of other items in the survey questionnaire. ${ }^{15} \mathrm{Z}$-score is considered to be the best of all the statistical measures because it includes variability, has high precision since mean is included in the calculation, and the results fall in the middle of other statistical measures.

When the students were asked to express the good aspects of the training involving key points, they responded with lot of thoughtful, good and appropriate answers. (Figure1). The responses were coded under seven headings such as presentation, learning, exam-oriented, list of topics, marks related, time of upload and developing interest in the subject.

\section{Presentation (36\%):}

- $\quad$ key points were useful in knowing what the particular topic was about

- low stress, easy understanding, best for last minute preparation
- answers were precise, given to the point and helped in better understanding of subject

- concise, no beating around the bush

- for some topics extra points were given

- diagrams \& flow charts were good for topics which are tough to understand in the text book

In a study, students showed steady increase in use of e-learning resources as the academic year progressed. That also showed that there was decline in the number of students using textbooks. This could be due to the fact that the students could have found that the e-resources provided concise information which could help in exam preparation or they could have found that it took longer time to prepare the same from the textbooks. ${ }^{6}$

\section{Learning (24\%):}

- concepts were explained clearly, it was easy to get an idea before reading text book

- easier to understand, makes studying easier, easy to remember and recollect

- decreased the amount of subject we had to study, we can study a lot

- gain more knowledge in short time, it was really interesting and resourceful

Performance of students in either formative or summative assessments depends on the extent of their understanding of the subject and their ability to focus on its most important elements. It gives the student a sense of mastery over the subject and improved their confidence to perform well in the examination. This could encourage them to like the subject. This could help them to become selfdirected learners as they progress further into the clinical phase of the medical course. ${ }^{6}$ Keller Plan has instructed a self-paced, personalized system of instruction (PSI) which consists of masteryoriented and individually-paced courses which used few lectures for stimulation and motivation, printed study guides for communication of information, and involved student proctors for quiz evaluation. ${ }^{20}$ The student-centered activities have brought improvements in teaching biochemistry at the University of Brasi'lia. ${ }^{13}$ There should be a congruency between student understanding of Biochemistry and the scientific concept. ${ }^{21}$ This is possible by providing accurate references in the specific manner, such as books, 
chapters, and page numbering, etc. after each objective. ${ }^{22}$

\section{Exam-oriented (15\%):}

- simple language, easy understanding and colour differentiation of points to emphasis the necessity of what to write in exam

- score more marks with less effort

- it contains only the most important points of the question; very useful as a guide

- best aspect was that key points are put up in one place, in a short form

In the early years, all the students tend to have insufficient background to make their studies understandable and enjoyable; later when they start understanding the subject, they may become overwhelmed by the mass of information. ${ }^{23} \mathrm{New}$ information keeps getting updated at an exponential rate with the old information being periodically re-assessed for its accuracy and specificity. Generally the assessments are in such a way that the student is expected to remember finer details, and reproduce the entire information. The interesting fact is that the majority of the students find biochemistry interesting, exciting, fascinating and relevant. Different textbooks deliver the subject in different ways. Hence in the presence of these challenges and limitations, the students need time to mature and accumulate background and experience. Teachers ought to be more clear and specific and make positive efforts to understand the difficulties faced by the students and help them accordingly. ${ }^{24}$

\section{List of topics (11\%):}

- all topics were useful

- I didn't have to refer the textbook for any, as the handouts had all relevant materials printed into easy reach

In a study, the students who studied from the lecture presentations were scoring more marks than those who were studying only from textbooks. That made them to switch over to studying from the e-resources and which in turn fetched them more marks. ${ }^{6}$

\section{Marks in the exam(6\%):}

- enabled better scoring in exams as it was easier than textbook learning

- key points made us pass the exam with ease. It was easy to learn smaller notes

- the best aspect is that it has helped us to pass the exams when compared to the other two subjects makes exam preparation ease

The students could perform better with an outline about the important points to be written and the proper presentation of the given topics.

\section{Time related (4\%):}

- Can access any time

- quick revision, useful for revision before the exams

E-learning resources are being used to facilitate self-directed learning. They were made available to supplement conventional lecture-based teaching. These resources made a positive impact on various aspects of their learning in biochemistry. ${ }^{6}$

\section{Developed interest in Biochemistry (4\%):}

- it made biochemistry easy \& interesting to learn, motivated me to read more and improved academic performance

- I have started liking Biochemistry Research work needs prioritization

- Condensed form of answers were very useful, helped me to gain more knowledge $\&$ interest towards the subject

- it primes us towards reading the entire topic thoroughly \& understanding the concepts

- Gives an idea about the subject, helpful in future use

By learning from teacher guides, around $80 \%$ of students had improved academic performance which paved the way for developing interest in Biochemistry as a subject and had developed motivation to study more. ${ }^{6}$

Students also gave their comments regarding the areas needed improvement and they have reasonably achievable suggestions. The responses were coded related to contents, time of upload, diagrams and flow charts, no improvement needed, search provision, question and answers type, hard copy marks allotted, clinical orientation, interactive and research.

\section{Content related (26\%):}

- the units would have been in order

- it could have been improved graphically

- the continuity was lost between two points

- answers not given to every question

- $\quad$ need more detailed points

The student's primary aim is to pass in the examination, hence not all topics were included. A good performing candidate could include extra 
points from the text book. These key points were used only for priming them which in turn would help them perform better.

Time of upload $(22 \%)$ :

- notes can be put up earlier

- could be given to as at the start of the academic year

- Should be uploaded by the end of lecture rather than before exams

The key points were uploaded in the intranet almost after the end of the last didactic lecture. If uploaded earlier all the students would resort to these points only which could limit the student's knowledge. Hence by providing the students with key points in the last minute, at least few students would make an attempt to start studying from the textbook. Otherwise in the long run the habit of self-directed learning would be lost. Hence the students should be periodically informed that these guides were only supplementary and could not replace the prescribed textbooks. ${ }^{6}$

Diagrams \& flow charts (20\%):

- diagrams can be more clear

- graphical representation and flow charts

- more flowcharts \& important key points for every chapter

Flow charts which were already in the textbooks were not included, which the student could study by himself/herself.

\section{No improvement needed (10\%):}

- its good, no improvements

This response could be either from a low performing student who would have thought what was provided as key points was more than sufficient; or it could be from a good performing student who did not hesitate to study from the textbooks.

\section{Search provision $(6 \%)$ :}

- search columns can be included, so it can be easier to find answers during university exams

- could be sent as mail for easy accessibility

- network issues with downloading the answers

It was felt the students responsibility is to surf the readily available key points.

\section{Q \& A included (5\%):}

- should involve $Q$ \& A format, not just random points, involve a little more explanatory format
- the key prints should be given as per the questions

The key points were provided as topics with the relevant information. Few students learn only examination relevant materials. They want Biochemistry to be presented in bullet point format which are easy to recall during board examinations. ${ }^{25}$

\section{Hard copy (4\%):}

- if it is given as a hand book or hard copy, it would be better

The key points were meant to be used as guides; it is highly impossible to replace printed textbooks with handouts.

\section{Marks Distribution (2\%):}

- mark allotment for each point

Since it was not a questions and answers format, mark distributions were not given.

\section{Clinical oriented (2\%):}

- more clinical knowledge

All the topics which were given to them had relevant clinical informations also. The students were unaware of the fact that knowledge of the basic sciences was mandatory to interpret the clinical problem. Modern medicine could not be practiced without understanding the genetic, pathogenic and environmental factors that affect the human body at the biochemical level. Medically relevant biochemistry is the one that gives students just the enough information to understand the basic mechanism of a biochemical defect and potential avenues of diagnosis and treatment. ${ }^{25}$

\section{Interactive(2\%):}

- more interactive session to discuss about the key points

The student should prepare themselves for the didactic lectures by reading the relevant information in textbooks, listen to the lecture in the class as well as they should not refrain from interacting with teachers or peers. ${ }^{26}$

\section{Research (1\%):}

The students should be trained to become independent learners, and be able to critically read and understand biomedical literatures and participate in biomedical research projects. ${ }^{25} \mathrm{~A}$ study at the University of São Paulo had explored the idea of using published research articles to teach metabolism instead of didactic lectures and seminars. Effectiveness of team-based learning (TBL) to teach the principles of medical 
biochemistry was positively evaluated by a study from Korea. Combining didactic lectures with group discussions, tutorials, problem-based approach, and seminars enhance learning and retention in memory. ${ }^{27}$

Acknowledgements:

Dr Santhi Silambanan expresses her gratitude to the management of SRIHER in giving permission to do this project as part of Advancement Course in Medical Education. Dr Santhi Silambanan also expresses her gratitude to the members of Medical Education Unit at Christian Medical College, Vellore for allowing and guiding to complete the course Advanced Course in Medical Education. All the authors express their sincere thanks to all the students who participated in the study.

\section{Authors' contributions:}

All authors, SS, AM, LS and RK shared in planning, conducting, analyzing the results, and writing the manuscript of this work. All authors read and approved the final manuscript.

Funding: No funding was obtained from any national or international bodies for conducting this study or publishing this article

Availability of data and materials: The datasets used during the current study are available upon request from the corresponding author.

Ethics approval and consent to participate: Ethics approval was obtained from the Institutional Ethics Committee of SRIHER. (IECNI/16/AUG/55/63, dated, 29-09-2016). All the study participants were included in the study after obtaining consent from them.

\section{Consent for publication:}

All authors have read the manuscript and agreed to all its contents. All authors gave their consent for publication.

\section{Competing interests:}

The authors declare that they have no competing interests.

\section{References}

[1] Jessica J. Vanderlelie. Improving the Student Experience of Learning and Teaching in Second Year Biochemistry: Assessment to Foster a Creative Application of Biochemical
Concepts. International Journal of Innovation in Science and Mathematics Education 2013; 21(4):46-57.

[2] Kulkarni SP, Patil VS, Patil VP, Ingleshwar DG, Shilpasree AS, Vani AC, et al. Combination of Multiple Teaching Tools in learning Biochemistry: Perceptions of Medical Undergraduate Students. Indian J Med Biochem 2018;22(1):41-46.

[3] Sanaa Eissa, Reem M Sallam, Amr S Moustafa, Abdelrahman MA Hammouda. Large-scale application of case-based learning for teaching medical biochemistry: a challenging experience with positive impacts. Eissa et al. Innov Educ 2020; 2:1.

[4] Rekha K, Namrata K, Shailesh K, Anand S, Uday K. Introduction Of Case Based Learning In Teaching Of Biochemistry. Natl J Integr Res Med 2016; 7(5): 82-86.

[5] Dantu Padmasree, Ukey Ujwala U, Kamala Kanta Parhi Teaching-learning methods in Biochemistry: First MBBS students' preferences and expectations.International Journal of Health Research in Modern Integrated Medical Sciences. 2015;2(2):2630 .

[6] Joe Varghese, Minnie Faith, Molly Jacob. Impact of e-resources on learning inbiochemistry: first-year medical students' perceptions. BMC Medical Education 2012, 12-21.

[7] C.V. Anand, U. Anand, R. Agarwal. Teaching biochemistry to medical students as per the revised curriculum of the medical council of India. Biochemical Education 1999;27: 240.

[8] P Finbarr Duggan, Colin A Ross. Teaching Biochemistry and Medical Biochemistry to Medical Students. 615th Meeting, Belfast:467.

[9] Ross S. Feldberg. Increasing student involvement in lectures: (very) low tech innovations in a biochemistry lecture class. Biochemical Education 1999;27: 71-73.

[10]Ethel L. B. Novelli, Ana Ange' lica H. Fernandes. Students' Preferred Teaching Techniques for Biochemistry in Biomedicine and Medicine Courses. Biochemistry and 
Molecular Biology Education 2007;35(4): 263-266.

[11] KrishnaM. Surapaneni \& Ara Tekian. Concept mapping enhances learning of Biochemistry. Medical Education Online 2013;18(1):20157.

[12] Ramesh Ramasamy, Niranjan Gopal, Srinivasan AR, Sathish Babu Murugaiyan. Planning an Objective and Need Based Curriculum: The Logistics with Reference to the Undergraduate Medical Education in Biochemistry. Journal of Clinical and Diagnostic Research 2013;7(3):589-594.

[13] Alexandre B Se, Renato M. Passos, Andre' H. Ono, Marcelo Hermes-Lima. The use of multiple tools for teaching medical biochemistry. Adv Physiol Educ 2008;32: 38-46.

[14]Constantin Mircioiu, Jeffrey Atkinson. A Comparison of Parametric and NonParametric Methods Applied to a Likert Scale Pharmacy 2017; 5:26.

[15] McLeod, S. A. (2019, August 03). Likert scale. Simply Psychology. https://www.simplypsychology.org/likert-scale.html

[16]Spencer E Harpe. How toanalyzeLikertandotherratingscaledata. Currents in Pharmacy Teaching and Learning 2015; 7:836-850.

[17] Gail M. Sullivan, Anthony R. Artino Jr, Analyzing and Interpreting Data From LikertType Scales. Journal of Graduate Medical Education 2013:541-542.

[18] De Winter JCF, D Dodou. Five-Point Likert Items: $t$ test versus Mann-WhitneyWilcoxon, Practical Assessment, Research and Evaluation 2010:15(11).

[19]Dr. Del Siegle's home page, Neag School of Education, University of Connecticut (http://www.gifted.uconn.edu/siegle/research/instrume nt\%20Reliability\%20and\%20Validity/Likert.html)

[20] Robert E Beyer. Learning Biochemistry at the Mastery Level Introductory Biochemistry at The University of Michigan. Biochemical Education1990; 18(2):82-87.

[21] Trevor R. Anderson, L Gail Crossley, Diane J Grayson. Identifying students' conceptual and reasoning difficulties with biochemistry. PoS1-4.

[22] Marikar FMMT, Wadige KNH, Lakmuthu SD, Priyanthi MYW, Perera PAJ. Evaluation of the Teaching Approaches of Biochemistry for Medical Students: A Sri Lankan Case Study. J Community Med Health Educ 2015;5(4): 359.

[23] Dinesh Puri. An Integrated Problem-Based Curriculum for Biochemistry Teaching in Medical Sciences. Indian Journal of Clinical Biochemisty 2002;17(2):52-59.

[24]E J Wood. Biochemistry is a Difficult Subject for Both Student and Teacher. Biochemical Education 1990;18(4):170-172.

[25] Mehdi Afshar \& Zhiyong Han. Teaching and Learning Medical Biochemistry: Perspectives from a Student and an Educator. Med.Sci.Educ 2014; 24:339-341.

[26] Doris Norwell. Tips -- How to Succeed as a Biochemistry Student. Biochemical Education 1991;19(2):75-76.

[27] Vadakedath S, Kandi V (August 16, 2019) Modified Conventional Teaching: An Assessment of Clinical Biochemistry Learning Process Among Medical Undergraduate Students Using the Traditional Teaching in Combination with Group Discussion. Cureus 11(8): e5396. 